BLS 33, No 1 2007. DOI: http://dx.doi.org/10.3765/bls.v33i1.3514

(published by the Berkeley Linguistics Society and the Linguistic Society of America)

\title{
The Evolutionary Phonology of Glottal Stops in K'ichean
}

\author{
RUSTY BARRETT \\ University of Kentucky
}

\section{Introduction}

This paper outlines historical changes involving glottal stop in K'ichean languages, including two regular sound changes involving glottal stop as an innovation and two phonological changes related to changes in morphology or phrasal phonology. The regular sound changes are phonetically-motivated changes of the sort that Blevins $(2004,2006)$ categorizes as "natural" changes and have regular patters of dialectal distribution. The other changes show widespread variation both across and within dialects and languages.

K'ichean Proper includes six closely-related Mayan languages spoken in the highlands of Guatemala: K'iche' (Mondloch 1978, Ajpacaja et al. 1996, López Ixcoy 1997, Par and Can 2000), Achi (Sis Iboy 2002), Kaqchikel (García Matzar and Rodríguez Guaján 1997, Patal et al. 2000, Cojtí et al. 2001), Tz'utujil (Dayley 1985, García Ixmatá 1997, Pérez and Mendoza 2001), Sakapuletko (DuBois 1981) and Sipakapense (Barrett 1999). K'iche' and Achi are sometimes considered dialects of a single language based on their linguistic similarity, but are treated as separate languages for social and political reasons (cf. Sis Iboy 2002). Achi is spoken to the east of K'iche', with Kaqchikel and Tz'utujil south of K'iche'. Sakapulteko is spoken in the town of Sacapulas in the northern part of the K'iche' region, while Sipakapense is spoken far to the west in an area dominated by speakers of Mam (another Mayan language that is not part of $\mathrm{K}$ 'ichean). The genetic relationships between the K'ichean languages are presented in (1) below. 
(1) Genetic relationships in K'ichean Proper (DuBois 1981, Barrett 1999)

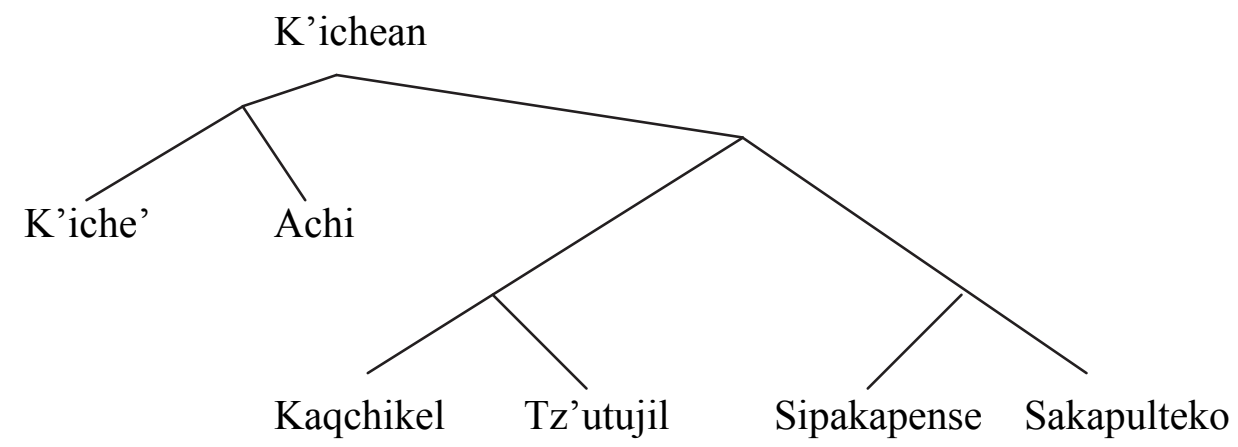

\section{Glottal stop as an innovation}

There are two patterns of innovative glottal stop in K'ichean, both involving the loss of oral place of articulation. The first involves debuccalization of word-final bilabial implosives. The second involves the backing and lowering of the voiceless uvular ejective.

\subsection{Word-final debuccalization in Southern K'ichean}

The loss of oral place for word-final bilabial imposives $/ \mathrm{b}$ '/ is a distinguishing characteristic of the southern K'ichean languages, Tz'utujil and Kaqchikel (Grimes 1969, Campbell 1977). The sound change *b' > ? occurred word-finally in words with more than one syllable. Roots that are b'-final maintain the bilabial under suffixation (compare the words for "night" and "dawn" in the data below). Examples of correspondences demonstrating this change are given in (2) below.

$$
\text { [b']:[?] correspondences in K'ichean }
$$

\begin{tabular}{|c|c|c|c|c|}
\hline Tz'utujil & Kaqchikel & K'iche' & Sipakapense & gloss \\
\hline aq'a? & aq'a? & aq'ab' & aq'ab' & night \\
\hline aq'ab'il & aq'ab'il & aq'ab'il & aq'ab'il & dawn \\
\hline छo?o? & wo?o? & Eo?ob' & $\Xi ? \mathrm{ob}^{\prime}$ & five \\
\hline$\Xi a a b^{\prime}$ & $\Xi \mathrm{ob}^{\prime} \sim \mathrm{\Xi ab}^{\prime}$ & $\Xi a a b ’$ & Eaab' & rain \\
\hline
\end{tabular}

\subsection{Merger of glottal stop and uvular ejective in Eastern K'ichean}

The other innovative occurrence of glottal stop is an unconditioned sound change in eastern dialects of K'iche' and in Achi (Par and Caan 2000). The uvular ejective /q'/ has changed to glottal stop in Cubulco (Achi). The neighboring communities to the southeast, Joybaj (K'ichee') and Rabinal (Achi), show variation between glottal stop, the uvular ejective, and a pharyngeal stop [ $\aleph$ ]. The towns further to the east and north, (Chicaj and Cunén) show a similar pattern, but 


\section{Evolutionary Phonology of Glottal Stop in K'ichean}

with a clear predominance of the uvular ejective. Thus, the change is complete in Cubulco, at an intermediary stage in Joyobaj and Rabinal and just spreading to Chicaj and Cunén. Correspondence sets demonstrating this change are given in (3) below.

(3) Changes in back consonants in Eastern K'iche' (cf. Par and Can 2000)

\begin{tabular}{|c|c|c|c|c|}
\hline gloss & sun, day & fire & night & bean \\
\hline Cubulco (Achi) & ?iin & ?an & ?a?am' & kina? \\
\hline Rabinal (Achi) & q'iiछ & ?aa? ?aaふ & ?aふam’ & kinas \\
\hline Joyobaj & ?ii $\Xi$ & ?aa? q'aaq' & ?aq'ab' ?a?ab' & kina? \\
\hline Cunén & q'iih $\sim$ q'ih & ?aa? & ?aq'ab' & kina? \\
\hline Chicaj (Achi) & q’ii & ?aaq' & ?aq'am' & kinas \\
\hline Other K'iche' & $\mathrm{q}^{\prime} \mathrm{ii} \Xi \sim \mathrm{q}^{\prime} \mathrm{i} \Xi$ & q'aaq' & ?aq'ab' & kinaq' \\
\hline
\end{tabular}

\subsection{Changes in intervocalic glottal stops}

In their reconstructions of proto-K'ichean phonology, both Grimes (1969) and Campbell (1977) note a correspondence between V?V and V? in K'iche'. Both Grimes and Campbell treat this correspondence as the result of a regular sound change, although they disagree on the form in proto-K'ichean, with Grimes choosing *V? and Campbell choosing *V?V. As Campbell's choice fits with independent reconstructions for proto-Mayan (Kaufman 2003), I will assume that $* \mathrm{~V}$ ?V is the proto-K'ichean form. This is a regular sound change, ${ }^{*} \mathrm{~V}$ ? $\mathrm{V}>\mathrm{V}$ ? in K'iche', following the patterns for vowel hiatus described by Casali (1997).

This change in intervocalic glottal stops is regular and exceptionless in roots where both vowels are short (e.g. *ts'a?am > ts'a?m, nose in all dialects). However, in cases where the second vowel was long in proto-Mayan, there is widespread variation in the K'iche' reflexes (and moderate variation in Sipakapense, Kaqchikel and Tz'utujil). In contrast, reflexes of proto-Maya *V?VV may have many forms in K'iche', including /?V/, /V? V/, /V?VV/, /V?/, $/ \mathbf{V V} /$, and $/ \mathrm{V} /$. Multiple forms are found as reflexes of $* \mathrm{~V}$ ? VV roots in the same dialect and the distribution of forms rarely extends beyond a single town. While a few towns show a regular pattern, such as all roots as V? in the K'iche' of Momostenango, most dialects have highly irregular distributions. In the dialect region of Nahualá and Santa Catarina Ixthuacán, these forms alternate, following an older pattern from Colonial K'iche' discussed below. Tables (4) and (5) demonstrate the variation in the reflexes of the proto-K'ichean roots for meat and skin, based on dialectal data from Par and Caan (2000). 


\section{Rusty Barrett}

(4)

Dialectal variation in the K'iche' word for "meat"

\begin{tabular}{|c|c|}
\hline \multicolumn{2}{|c|}{ *ti?ii $\Xi$ (proto-K'ichean) "meat" (cf. Par and Caan 2000) } \\
\hline $\mathrm{t}-? \mathrm{i} \Xi(=? \mathrm{~V})$ & San Antonio Ilotenango, Zacualpa \\
\hline ti?ii $\Xi(=\mathrm{V} ? \mathrm{VV})$ & $\begin{array}{l}\text { San Miguel Chicaj, Zunil, Santa Clara la Laguna, } \\
\text { Momostenango }\end{array}$ \\
\hline ti? $\Xi(=V ?)$ & Totonicapán, Cunén, Santa Cruz de El Quiché \\
\hline ti?i $\Xi(=V ? V)$ & Joyabaj, Chichicastenango \\
\hline
\end{tabular}

Dialectal variation in the K'iche' word for "skin"

\begin{tabular}{|l|l|}
\hline \multicolumn{2}{|c|}{ *tz'uhuum (proto-K'ichean) “skin” (cf. Par and Caan 2000) } \\
\hline ts'u?uum (=V?VV) & Santa Lucia Utatlan \\
\hline ts'uum (=VV) & Santa Clara la Laguna \\
\hline ts'um (=V) & Chichicastenango, Cantel, Santa Maria Chiquimula \\
\hline ts'u?m (=V?) & Joyobaj \\
\hline
\end{tabular}

In addition to widespread variation in a particular root across dialects, contemporary forms originating from $* \mathrm{~V}$ ?VV roots show widespread variation within a single dialect. Table (6) below, demonstrates the variation in these forms across dialects of Achi and K'iche'. The dialects are arranged geographically, moving from east to west. Note that although the word for "skin" displays an irregular pattern, forms with a single vowel (CVC) predominate.

(6) Variation in three *V?VV roots in K'iche'

\begin{tabular}{|c|c|c|c|}
\hline towns, east to west & $\begin{array}{l}\text { *ti?ii } \Xi \\
\text { "meat" }\end{array}$ & $\begin{array}{l}\text { *ts'uhuum } \\
\text { "skin" }\end{array}$ & $\begin{array}{l}\text { *k'a?aam } \\
\text { "straw" }\end{array}$ \\
\hline Chicaj (Achi) & V?VV & $\mathbf{V} ?$ & V?V \\
\hline Rabinal (Achi) & V? & V?V & V?V \\
\hline Cubulco (Achi) & $? \mathrm{~V}$ & -- & V?V \\
\hline Joyobaj & V?V & $\mathbf{V} ?$ & $\mathbf{V V}$ \\
\hline Zacualpa & ?V & $\mathbf{V}$ & $\mathbf{V}$ \\
\hline Cunén & V?VV & $\mathbf{V}$ & V? \\
\hline Chichicastenango & V?V & $\mathbf{V}$ & $\mathbf{V}$ \\
\hline Santa Cruz del Quiché & $\mathbf{V} ?$ & $\mathbf{V}$ & V? \\
\hline San Antonio Ilotenango & $? \mathbf{V}$ & -- & V?VV \\
\hline Santa Clara la Laguna & V?VV & VV & V?V \\
\hline Santa Lucía Utatlán & V?VV & V?VV & V?VV \\
\hline Momostenango & $\mathbf{V} ?$ & V? & V? \\
\hline Cantel & $\mathbf{V} ?$ & $\mathbf{V}$ & $\mathbf{V} ?$ \\
\hline Zunil & V?VV & $\mathbf{V} ?$ & V?V \\
\hline Samayac & V?VV & $\mathbf{V} ?$ & V?V \\
\hline
\end{tabular}




\section{Evolutionary Phonology of Glottal Stop in K'ichean}

\subsection{Synchronic alternations of V?VV sequences in Classical K'iche'}

The widespread variation in proto-K'ichean ${ }^{*} \mathrm{~V}$ ?VV reflexes is the result of analogical leveling of allophonic variation in earlier K'iche'. In the K'iche' of the Popool Wuuj (transcribed around 1700), roots with the form CV?VVC show allophonic variation according to morphological and phrasal contexts (Dürr 1987). In Classical K'ichee', CV?VVC roots had the form CVC when followed by a derivational suffix. Phrase-medially, they had the form CV?C and only maintained the form CV?VVC in phrase-final position. The alternation can be seen in the ways in which the word for "skin" (ts'u?uum) is written in the Popol Wuuj. Note that the orthography of the Popol Wuuj does not represent vowel length. The vowel length can be reconstructed from the dialects that preserve this

alternation (Nahualá and Santa Catarina Ixthuacán). Table (7) shows the synchronic variation in the word for "skin" as found in the Popool Wuuj (cf. Dürr 1987).

Forms of the word "skin" (ts'u?uum) in the Popool Wuuj

\begin{tabular}{|l|l|l|l|}
\hline environment & & & gloss \\
\hline phrase-final & ...tz'u'um. & V?VV & ...skin \\
\hline phrase-medial & ri tz'u'm Pasilisib' ub'i. & $\mathbf{V} ?$ & $\begin{array}{l}\text { the skin named } \\
\text { Pasilisib' }\end{array}$ \\
\hline suffixed & xa utz'umal chikop & $\mathbf{V}$ & only an animal's skin \\
\hline
\end{tabular}

The irregular distribution in proto-K'ichean ${ }^{*} \mathrm{~V}$ ?VV reflexes results from analogical leveling combined with the loss of these synchronic alternations. It is not surprising that the root for "skin" shows a much higher distribution of forms without a glottal stop, given that this root typically occurs as a possessed form which requires the suffix $+a l$. In Colonial K'iche', suffixed forms did not include the underlying glottal stop when a root occurs with a suffix.

The alternations in $* \mathrm{~V}$ ?VV roots are still found in the dialects of Nahualá and Santa Catarina Ixthuacán, where they are part of a larger set of alternations involving glottal stop in intervocalic position. Additional alternations occurring with intervocalic and word-final glottal stops are outlined in the following section.

\subsubsection{V?V-final forms}

In Nahualá K'iche', the prosodic alternation between phrase-medial V? and $\mathrm{V}$ ?VV forms is limited to forms in which both vowels are identical and are followed by a consonant (other than glottal stop). Instances of $\mathrm{V}_{1}$ ? $\mathrm{V}_{2}$ surface as $\mathrm{V}_{2}$ ? in most dialects of K'iche' and in Sipakapense (cf. Barrett 1993). Cases of V?V\# follow this pattern, surfacing as V?\# phrase-finally. Nahualá K'iche' verbs take modal agreement suffixes phrase-finally that do not occur phrase-medially, as with the root /b'an/ to do, make shown in (8) below. 


\section{Rusty Barrett}

(8) Modal agreement suffix in Nahualá K'iche':

(a) Kub'an_ri sub'. "S/He is making tamales"

(b) Are ri sub' kub'ano "It is tamales that s/he is making"

The suffix $+o$ (marking active transitive agreement) only occurs when the verb is in adjacent to the edge of a $\mathrm{CP}$, usually when phrase-final (as in example (b) above). In verbs with a root-final glottal stop, the root vowel is lost in the phrasefinal position due to a regular alternation in which underlying $\mathrm{V}_{1}$ ? $\mathrm{V}_{2}$ sequences surface as $\mathrm{V}_{2}$ ?. The examples in (9) demonstrate the loss of root vowel in this context in which the verb roots /ta?/ and /to?/ both surface as [to?] when followed by the modal agreement suffix $+o$.

(9) Modal agreement suffix with glottal-final roots

(a) Kinta? Eun ts'i?. "I hear a dog"

(b) Kinto? Eun ts'i?. "I help a dog"

(c) Are Eun ts'i? kinto? "It's a dog I hear" $(/ \mathrm{ta} ?+\mathrm{o} /)$

(d) Are छun ts'i? kinto? "It's a dog I help" (/to?+o)

\subsubsection{Word-final glottal stops}

All K'ichean languages have alternations involving the loss of word-final glottal stops when followed by a consonant in the same phonological phrase. Languages vary, however, in the exact ways in which this alternation occurs. In Tz'utujil, for example, final glottal stop is deleted phrase-medially regardless of the length of the preceding vowel. The examples in (10) demonstrate this alternation for a preceding long vowel (a) and a preceding short vowel (b).

(10) Loss of final glottal stop phrase-medially in Tz'utujil (Dayley 1985:49):

(a) b'aarkii? "where"

b'aarkii k'o wi? "where is it?"

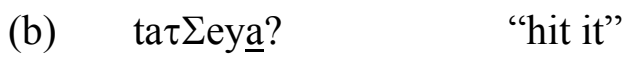

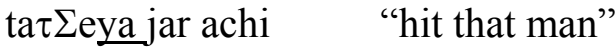

The pattern in K'iche' is different, in that the phrase-internal glottal stop deletes only when preceded by a short vowel. Loss of the glottal stop also involves compensatory lengthening, so that a /V?/ sequence surfaces as [VV] in phrase-medial position. The distinction is presented in (11) below, where the forms involving a long vowel (those in (a) below) do not show glottal stop deletion. The forms in (b) involve a preceding short vowel and demonstrate the pattern of glottal-deletion with compensatory lengthening. 


\section{Evolutionary Phonology of Glottal Stop in K'ichean}

(11) Patterns of final glottal stop in K'iche':

(a) Are $\Xi$ un nimala $\Xi \tau \Sigma$ eee?

K’o $\Xi$ un $\tau \sum \underline{\text { eee}}$ ? sib'ala $\Xi$ niim.

(b) Are $\Xi$ un nimala $\Xi$ ts'i?

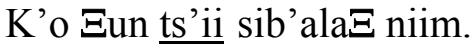

"That is a really big tree."

"There is a tree that is really big."

"That is a really big dog."

"There is a dog that is really big."

The phrase-level alternations involving glottal consonants in Nahualá K'iche' also interact with a separate pattern involving the deletion of final consonants in CVC clitics. Post-verbal CVC clitics show an alternation between phrase-final and phrase-medial forms, with the final consonant deleting phrase-medially. The pattern is demonstrated in (12) below, where the clitic/ta $\Xi$ / (irrealis) surfaces as [ta] in non-final position.

Alternations in the verbal clitic /ta $\Xi$ / in Nahualá K'iche'

\begin{tabular}{|c|c|c|c|}
\hline & & example & gloss \\
\hline clitic-group-medial & ta & Na kimb'e ta $\tau \sum \mathrm{ik}$ & I am not going again. \\
\hline $\begin{array}{l}\text { clitic-group-final, } \\
\text { phrase-medial }\end{array}$ & ta & $\begin{array}{l}\text { Na kimb'e ta [pa } \\
\text { k'ayb'al }]_{P P}\end{array}$ & $\begin{array}{l}\text { I am not going to the } \\
\text { market. }\end{array}$ \\
\hline $\begin{array}{l}\text { clitic-group-final, } \\
\text { phrase-final }\end{array}$ & $\operatorname{ta} \chi$ & Na kimb’e ta $\Xi$ & I am not going. \\
\hline
\end{tabular}

This alternation interacts with the loss of final glottal consonants with compensatory lengthening described above. In cases where the final consonant of a CVC clitic is glottal (either h or ?), there are three distinct surface forms. In cases where the $\mathrm{CVC}$ clitic is followed by another clitic, the glottal consonant deletes following the regular pattern in (12) above. If the CVC clitic occurs at the end of the clitic group, but is still phrase-medial, the pattern of final loss with compensatory lengthening occurs. In cases where the clitic is phrase-final, the full CVC form occurs. The examples in (13) below show these alternations for two glottal-final clitics, /nah/ (marking obligation or future) and /lo?/ (marking possibility or probability).

(13) Alternations in the verbal clitics /nah/ and /lo?/ in Nahualá K'iche'

\begin{tabular}{|l|l|l|l|}
\hline clitic-group-medial & na & Kimb'e na $\tau$ ¿ik & I will go again. \\
\hline $\begin{array}{l}\text { clitic-group-final, } \\
\text { phrase-medial }\end{array}$ & naa & Kimb'e naa [pa k'ayb'al $]_{\mathrm{PP}}$ & $\begin{array}{l}\text { I will go to the } \\
\text { market. }\end{array}$ \\
\hline $\begin{array}{l}\text { clitic-group-final, } \\
\text { phrase-final }\end{array}$ & nah & Kimb'e nah & I will go. \\
\hline
\end{tabular}


Rusty Barrett

\begin{tabular}{|l|l|l|l|}
\hline clitic-group-medial & lo & Kimb'e lo $\tau$ ¿ik & I might go again. \\
\hline $\begin{array}{l}\text { clitic-group-final, } \\
\text { phrase-medial }\end{array}$ & loo & Kimb'e loo [pa k'ayb'al $]_{\mathrm{PP}}$ & $\begin{array}{l}\text { I might go to the } \\
\text { market. }\end{array}$ \\
\hline phrase-final & lo? & Kimb'e lo? & I might go. \\
\hline
\end{tabular}

\section{Initial glottal stop}

In all K'ichean languages, syllable onsets are obligatory so that epenthesis of an initial glottal stop occurs for unprefixed vowel-initial roots. K'ichean languages have two distinct sets of possessive prefixes corresponding to vowel-initial and consonant-initial roots. The distinction is demonstrated with examples from K'iche' in (14) below (the pattern occurs for all prefixes, although only the firstperson singular is given here).

$$
\text { Possessive prefixes in K'iche' }
$$

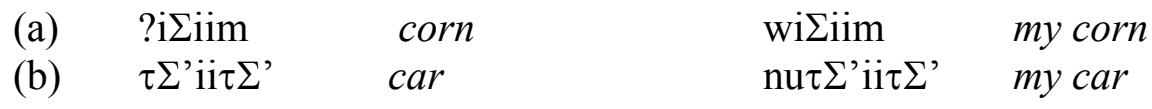

The form in (a) above shows an initial glottal in isolation, but takes the "vowelinitial" prefix $(w+)$ without the glottal stop when possessed. The forms in (b) show the "consonant-initial" prefix. This pattern holds for possessive prefixes across $\mathrm{K}$ 'ichean languages, however with the agentive prefix /a $\Xi++++/$, vowelinitial roots surface with an initial glottal stop, as demonstrated in (15) below.

(15) The agentive suffix /a $\Xi++++/$ with a vowel-initial root in K'iche'

$$
\text { ?iik’ month a } \Xi \text { ?iik' worker paid by the month }
$$

While the overwhelming majority of noun roots follow the pattern corresponding to that in (14) above, all K'ichean languages contain a small set of vowel-initial roots that always occur with an initial glottal stop and regularly take the "consonant-initial" possessive prefixes. Compare the form in (16) below with those in (14) above.

$$
\text { Possession on a noun root with an underlying initial glottal (Nahualá) }
$$

$$
\text { ?a } \Sigma \mathrm{uu} \Sigma \text { garlic nu?a } \quad \mathrm{uu} \Sigma \quad \text { my garlic }
$$

The roots with an initial glottal stop vary widely across languages and dialects. However, forms with an initial glottal stop are typically those forms that are borrowed from Spanish or nouns that are very rarely possessed. For example, the root in (16) does not have an initial glottal in most other dialects of K'iche' (where the possessed form is regular, $[\mathrm{wa} \Sigma \mathrm{uu} \Sigma]$ ). These roots show variation in sub-dialects as well. For example, the noun meaning bromeliad shows variation 


\section{Evolutionary Phonology of Glottal Stop in K'ichean}

between Nahualá and Santa Catarina Ixthuacán, neighboring towns generally assumed to form a single dialect of K'iche'. Examples of this form are given in (17) below.

(17) Forms for bromeliad in Nahualá and Santa Catarina Ixthuacán

$\begin{array}{ll}\text { ?eek' } & \text { "bromeliad” } \\ \text { week' } & \text { "my bromeliad" (Santa Catarina Ixthuacán) } \\ \text { nu?eek' } & \text { "my bromeliad” (Nahualá) }\end{array}$

Similarly local patterns are found in other K'ichean languages. The examples in (18) demonstrate variation in these forms from Kaqchikel (cf. Patal et al. 2000).

(18) Dialectal variation in possession of vowel-initial roots in Kaqchikel

$\begin{array}{ll}\text { nu?oko } \Sigma & \text { "my mushroom" (San Antonio Aguas Calientes) } \\ \text { woko } \Sigma & \text { "my mushroom" (elsewhere) } \\ \text { nu?o } \Xi & \text { "my avocado" (San Antonio Aguas Calientes) } \\ \text { wo } \Xi & \text { "my avocado" (elsewhere) } \\ \text { nu?i } \Sigma \text { in } & \text { "my corn" (San José Poaquil) } \\ \text { wi } \Sigma \text { in } & \text { "my corn" (elsewhere) }\end{array}$

The pattern in Sipakapense is similar (Barrett 1999). Although there is very little dialectal variation in Sipakapense, vowel-initial forms vary across areas of town. Non-final vowels in Sipakapense are generally deleted, so that both the "consonant-initial" and the "vowel-initial" prefixes result in forms with a CC onset. This is demonstrated in (19) below.

$$
\text { Sipakapense possession (first singular) }
$$

\begin{tabular}{|c|c|c|c|}
\hline $\begin{array}{l}\text { ?i } \text { iiim } \\
\text { ts'i? }\end{array}$ & $\begin{array}{l}\text { "corn" } \\
\text { "dog" }\end{array}$ & $\begin{array}{l}\text { w } \sum \text { iim } \\
\text { nts'i? }\end{array}$ & "my corn" (all dialects) \\
\hline
\end{tabular}

The word for "rabbit" shows three different variants, given in (20) below. In addition to the glottal-initial form that takes the preconsonantal prefix and the regular vowel-initial form, a third form occurs with the "consonant-initial" prefix and loss of the initial vowel. 


\section{Rusty Barrett}

Sipakapense words for "my rabbit"

?imul "rabbit" (all dialects)

wmul "my rabbit" (north)

n?imul "my rabbit" (west)

nmul "my rabbit" (east)

In addition to forms that are rarely possessed and borrowings from Spanish, Sipakapense forms with the agentive prefix $/ a \Xi++/$ always occur with an underlying initial glottal stop. In other K'ichean languages, these forms are regular vowel-initial roots. Examples are given in (21) below.

(21) Forms of the word for "teacher" in K'iche' and Sipakapense

Sipakapense: $a \Xi$ tii $\Xi$ "teacher" $\quad \mathrm{n}$ ? $\Xi$ tii $\Xi$ "my teacher"

K'iche': a $\Xi$ tii $\Xi$ "teacher" wa $\Xi$ tii $\Xi$ "my teacher"

Dialectal variation in the possession of vowel-initial roots is the most highly irregular form of variation in K'ichean languages, with variation occurring both within and across regional dialects.

\section{Conclusion}

The evolution of glottal stops in K'ichean demonstrates the distinction between "natural" and "unnatural" changes in evolutionary phonology (Blevins 2006). Regular ("natural" in Blevins framework) sound changes result in distinct dialect areas with regular isoglosses delineating regions that have undergone phonetically-motivated sound change. In contrast, "unnatural" changes related to morphological change result in irregular variation in which a single form in the proto-language corresponds to multiple forms in a individual dialects.

\section{References}

Ajpacaja Tum, Pedro Florentino, Manuel Isidro Chox Tum, Francisco Lucas Tepaz Raxuleu and Diego Adrian Guarchaj Ajtzalam. 1996. Diccionario K'iche' Guatemala: Cholsamaj/Proyecto Lingüístico Francisco Marroquín.

Barrett, Rusty. 1993. K'iche' Maya truncation and prosodic hierarchy theory. MA Report. University of Texas at Austin, Department of Linguistics.

Barrett, Rusty. 1999. A grammar of Sipakapense Maya. PhD dissertation. University of Texas at Austin.

Blevins, Juliette. 2004. Evolutionary phonology: The emergence of sound patterns. Cambridge: Cambridge University Press.

Blevins, Juliette. 2006. New perspectives on English sound patterns: 'Natural' and 'unnatural' in evolutionary phonology. Journal of English Linguistics 34(1): 6-25. 


\section{Evolutionary Phonology of Glottal Stop in K'ichean}

Campbell, Lyle. 1977. Quichean linguistic prehistory. University of California publications in linguistics; 8. Berkeley, CA: University of California Press.

Casali, Roderic F. 1997. Vowel elision in hiatus contexts: Which vowel goes? Language 73(3): 493-533.

Cojtí Macario, Narciso, Martín Chacah Cutzal and Marcos Armando Cali. 2001. Diccionario Kaqchikel. Guatemala: Cholsamaj/Proyecto Lingüístico Francisco Marroquín.

Dayley, Jon P. 1985. Tzutujil grammar. University of California pulbications in linguistics; 107. Berkeley, CA: University of California Press.

DuBois, John William. 1981. The Sacapultec language. PhD dissertation, University of California at Berkeley.

Dürr, Michael. 1987. Morphologie, Syntax und Texstrukturen des (Maya-)Quiche des Popol Vuh: linguistische Beschreibun eines kolonialzeitle. Bonn: Vom Verf.

García Ixmatá, Ajpub' Pablo. 1997. Rukeemik ja Tz'utujiil Chii'. Guatemala: Cholsamaj.

García Matzar, Lolmay Pedro and Pakal B’alam José Obispo Rodríguez Guaján. 1997. Rukemik ri Kaqchikel Chi': Gramática Kaqchikel. Guatemala: Cholsamaj.

Grimes, James Larry. 1974. Phonological history of the Quichean languages. Carbondale, Illinois. Southern Illinois University Museum Studies.

Kaufman, Terrence. 2003. A Preliminary Mayan Etymological Dictionary. Ms., University of Pittsburgh.

López Ixcoy, Saqijix Candelaria Dominga. 1997. Gramatica K'ichee' Guatemala: Cholsamaj.

Mondloch, James. 1978. Basic Quiché grammar. Albany, NY: Institute of Mesoamerican Studies, SUNY-Albany.

Par Sapón, María Beatriz and Telma Angelina Can Pixabaj. 2000. Ujunamaxik ri K'ichee' Ch'ab'al. Guatemala: Cholsamaj.

Patal Majzul, Filiberto, Lolmay Pedro Oscar Garcia Matzar and Ixchel Carmelina Expantzay Serech. 2000. Rujunamaxik ri Kaqchikel Chi'. Guatemala: Cholsamaj.

Sis Iboy, Nikte' María Juliana. 2002. Ri K’ichee' jay ri achi: La e ka 'iib' chi ch'ab'al? Tesis de licenciatura. Universidad Rafael Landívar.

Pérez Mendoza, Francisco and Miguel Hernández Mendoza. 2001. Diccionario Tz'utujil. Guatemala: Cholsamaj/Proyecto Lingüístico Francisco Marroquín. 